\title{
THE INVESTMENT EFFICIENCY OF THE SELECTED FOOD INDUSTRY COMPANIES LISTED ON THE WARSAW STOCK EXCHANGE IN THE YEARS 2007-2017
}

\author{
Dorota Zebrowska-Suchodolska', Ph.D.; Andrzej Karpio ${ }^{2,}$ Ph.D. \\ 1,2 Warsaw University of Life Sciences - SGGW
}

\begin{abstract}
The paper analyses the investment attractiveness of companies from the food industry listed on the Warsaw Stock Exchange. For this purpose, the Sortino, UPR and Omega coefficients calculated for companies operating on the market in the years 2007-2017 were used. Selected entities have over $90 \%$ share in the WIG-food index. The choice of effectiveness measures was dictated by the definition of risk often identified by investors with a loss. However, the period of research covers periods of worse and better stock market conditions, which is why it was decided for the years 2007-2017. For comparison purposes, these measures were also calculated for the following indices: WIG-food and WIG. The second index was included in the research to present the surveyed industry against the background of the entire exchange market. The calculations were based on daily percentage price changes. Basic measures of descriptive statistics were determined. The obtained values indicate the lack of normality of the rates of return, which eliminates the classic measures of investment efficiency. The results show that the capitalization of companies is important from the point of view of stock exchange investors. It determines the rankings created on the basis of performance indicators. However, closer research on the statistical properties of the measurements used shows that capitalization is important, but there must be other determinants. On the basis of the obtained results, it can be additionally stated that the leaders of the food market have also turned out to be attractive to investors on the entire stock exchange.
\end{abstract}

Key words: WIG-food, rating based on Sortino, rating based on UPR, rating based on Omega, correlations between ratings.

JEL code: G10, Q02

\section{Introduction}

One of the basic sectors of the economy is the food industry. Its condition can be studied in many ways. Data on individual units, dynamics of changes in the entire sector, share in GDP etc. are published. In the market economy, the results of research on entities listed on the stock exchange may be added to this information set. This is an important issue as it reflects investors' predictions and expectations regarding the condition of individual companies as well as the entire sector. Investors in the reported demand and supply issue a very strict assessment of the management of companies, their policies, skills and achievements. Therefore, the authors made an attempt to evaluate the food sector, represented by companies listed on the Warsaw Stock Exchange. It is made from the investors' point of view, which is why the basis for the analysis are selected investment efficiency ratios. The authors assume that it is investors who make the most reliable and objective assessment of companies. On the one hand, they risk their own capital, while on the other, investment efficiency is the result of assessments of many investors, not the subjective view of several or a few analysts. Therefore, the assessment of selected companies from the investment point of view is very important. The aim of the work is to verify the hypothesis that the food industry is attractive to stock exchange investors. The investors can find companies with performance indicators that are better than measures calculated for the industry as well as for the entire stock market. The subject of the research are companies included in the WIG-food sector index (WIG is the name of the main index of Polish stock exchange). It is calculated from 31 December 1998. At present, ${ }^{1}$ it consists of 24 companies, 14 of which remain in the index since 2007. Since the research has been carried out for the last 10 years, it have therefore concerned these companies. The authors decided for such a period for two reasons: first, 10 years is long

${ }^{1}$ Status on 30 January 2017. 
enough for statistical methods to be used and, secondly, it covers periods of better and worse economic conditions in the country and the world (2007 is the beginning of the global financial crisis). Consequently, the research concerns the following companies: Ambra, Astarta, Atlantapl, Colian, Gobarto, Helio, Indykpol, Kernel, Kruszwica, Makaronpol, Pamapol, Pepees, Seko, Wawel. The largest share in the index have ${ }^{1}$ Kernel $(48,6 \%)$ and Wawel $(16,9 \%)$, while the smallest: Pamapol (0,2\%) and Atlantapl (0,24\%). The surveyed entities account for $90 \%$ of shares in the WIG-food index, which is why they can be considered as representative for the food industry. In addition, the scope of activities includes both strictly agricultural activities, as well as food processing (e.g. Pamapol), as well as typically food production, such as confectionery (e.g. Wawel). It should also be added that among the listed entities are companies with economic activity registered in Ukraine (e.g. Kernel). However, the Polish market is one of the basic recipients of the offered products, and their presence on the Warsaw Stock Exchange influences the situation on the stock exchange; therefore, they have been included in the research.

In the research of investment effectiveness, the most commonly used are classical measures such as Sharpe, Treynor, Jensen etc. However, they require the normality of the distribution of percentage changes in prices. In the case of entities listed on stock exchanges, usually short-term rates of return (daily) do not have this property, which is why non-classical measures are applied then. This is the case in this work, the authors use daily changes in stock prices and therefore the studies are based on indicators: Sortino (Sortino, Price 1994), its modification leading to upside potential ratio UPR (Sortino et al., 1999) and the Omega indicator (Shadwick, Keating, 2002). In the first case, the formula is used:

$$
S=\frac{\bar{R}-m}{\sigma_{-}(m)}
$$

Where:

$\bar{R}=\frac{1}{N} \sum_{t=1}^{N} R_{t}, N$ is the amount of data, $R_{t}$ the rate of return in period $t$. The magnitude of $\sigma_{-}(m)$ is a risk measure defined by the formula:

$$
\sigma_{-}(m)=\sqrt{\frac{1}{N} \sum_{t: R_{t}<m}\left(R_{t}-m\right)^{2}}
$$

On the other hand, $m$ is a break-even point, which may be adopted at various levels, for example it may be equal to the benchmark average, which is usually the case when the research concerns collective investment institutions. Otherwise, it may be a risk-free rate. Thus, the Sortino index refers to the average excess rate of return $\bar{R}-m$ to the total risk taking into account only the losses, which are defined by the relation: $R_{t}-m<0$. Because in this work the break-even point was assumed to be $m=0$; therefore, the profit measure is a positive rate of return.

With the same markings as above, the UPR indicator defines the expression:

$$
U P R=\frac{\sum_{t: R_{t}>m}\left(R_{t}-m\right)}{\sigma_{-}(m)}
$$

${ }^{1}$ All values are given as of 30 January 2017. 
This measure is a modification of the previous one, because instead of the excess rate of return in the numerator, there is a measure of total profit in the analysed period.

The third measure of investment efficiency is the Omega indicator given by the formula:

$$
O=\frac{\frac{1}{N} \sum_{t: R_{t}>m}\left(R_{t}-m\right)}{\frac{1}{N} \sum_{t: R_{t}<m}\left(m-R_{t}\right)}
$$

It differs from the UPR risk measure, now it is the sum of the absolute loss values and not the modified standard deviation.

It should be added that in all the indicators used, the risk is identified with a loss. In the case of classical measures, the risk is a standard deviation (when referring to the total risk) or a beta factor in characteristic lines (market risk). For these reasons, they require the normality of returns. The authors decided on a loss as a measure of risk because it is treated in both its common understanding and in business.

Data for calculations was taken from the portals stooq.pl, bossa.pl i money.pl. Fundamental information about companies, the composition of WIG and WIG-food indices come from the website of the Warsaw Stock Exchange: gpw.pl. The data regarding the WIG broad market index and the WIG-food industry index were taken into account in parallel with the companies. This allows you to compare the ratios calculated for companies with their values for the industry and for the entire stock market.

\section{Selected descriptive statistics of companies from the food sector}

In the research, the rate of return was calculated according to the formula:

$$
R_{t}=\frac{c_{t}-c_{t-1}}{c_{t-1}}
$$

where $c_{t}$ is the price of the stock at the moment $t$, and $c_{t-1}$ in the previous moment. The work included daily closing prices from 1 January 2007 to 31 December 2017. Some companies appeared on the Polish stock exchange in the year 2007, when the data was slightly shorter than for the rest. This does not significantly affect the results, as the set of complete data included over 2.500 observations. The rates of return calculated according to the above formula do not come from the normal distribution. To prove this, the classic Shapiro-Wilk test was used (Dobosz, 2004), a significance level of 0.05 was assumed. For all companies, the zero hypothesis was rejected, assuming that the distribution of rates of return is a normal distribution. The basic measures of descriptive statistics are summarized in Table 1.

The table does not include the median, which at the adopted level of accuracy for all companies and indices was equal to zero. Based on the above data, it can be concluded that average daily rates of return differ from each other at most by order of magnitude and only two of them take negative values. In turn, standard deviations show a relatively small dispersion of values, ranging from $1.24 \%$ to $3.47 \%$. The volatility coefficients are relatively large, which means significant volatility in the prices of companies in the food industry. It should be noted that the volatility of the WIG-food index is almost twice as high as the WIG index. Which proves that not only the surveyed companies, but the entire industry was characterized by high volatility of prices of listed assets. It is noteworthy that Atlantapl, which had a volatility around 10 times the average for the food 
industry. It seems that the reason must lie in the foundations of the company. Kurtosis is positive and far from zero for all companies. Therefore, we deal with leptokurtic distributions of rates of return, which means that they are more concentrated than in the case of normal distribution centred around central moments. The coefficients of skewness are positive (the exception is Seko) and relatively small, so the distribution of rates of return is characterized by right-sided asymmetry of a small scale. At the same time, the indexes tested have left-hand asymmetry. Taking into account the industry index, it can be concluded that the asymmetry of the company is more strongly influenced by companies listed for less than 10 years.

Table 1

Descriptive statistics for the surveyed companies and indexes

\begin{tabular}{|l|c|c|c|c|c|}
\hline & Average ( \%) & $\begin{array}{c}\text { Deviation } \\
\text { standard ( \%) }\end{array}$ & $\begin{array}{c}\text { Coefficient of } \\
\text { variation( \%) }\end{array}$ & Skewness & Kurtosis \\
\hline AMBRA & 0.0462 & 2.5527 & 55.227 & 0.34059 & 7.125 \\
\hline ASTARTA & 0.0863 & 3.0494 & 35.338 & 0.39277 & 6.2957 \\
\hline ATLANTAPL & 0.0022 & 3.4498 & 1551.3 & 0.45512 & 4.8461 \\
\hline COLIAN & 0.0174 & 2.5492 & 146.65 & 0.39357 & 6.9509 \\
\hline GOBARTO & -0.0567 & 3.0367 & 53.59 & 0.20756 & 15.147 \\
\hline HELIO & 0.0390 & 2.9822 & 76.464 & 0.79553 & 6.9768 \\
\hline INDYKPOL & 0.0222 & 2.6082 & 117.74 & 0.02756 & 4.2153 \\
\hline KERNEL & 0.0640 & 2.7187 & 42.473 & 0.11937 & 5.6353 \\
\hline KRUSZWICA & 0.0229 & 2.3126 & 92.909 & 0.41444 & 5.4529 \\
\hline MAKARONPL & 0.0133 & 2.8481 & 213.75 & 0.35956 & 4.0868 \\
\hline PAMAPOL & -0.0744 & 3.4680 & 46.642 & 0.86431 & 10.693 \\
\hline PEPEES & 0.0614 & 3.2542 & 52.984 & 1.6259 & 14.402 \\
\hline SEKO & 0.0232 & 2.9413 & 126.7 & -0.0864 & 6.14 \\
\hline WAWEL & 0.0700 & 1.9697 & 28.138 & 0.27556 & 4.1343 \\
\hline WIG-SPOŻYWCZY & 0.0094 & 1.4897 & 158.68 & -0.1583 & 3.7484 \\
\hline WIG & 0.0157 & 1.2385 & 79.113 & -0.3682 & 4.056 \\
\hline
\end{tabular}

\section{Efficiency ratios of companies from the food sector}

As mentioned in the introduction, the key question to be answered by the work concerns the value of investment efficiency ratios. They play a key role in assessing the attractiveness of investments in shares of companies listed on the free market. The results of calculations of Sortino, UPR and Omega indicators are presented in the following charts. Each of them was ordered from the highest to the smallest value. The black columns were assigned to WIG and WIG-food indices. It should be added that the values of various efficiency factors are irrelevant, as the definitions are not comparable. Relevant values within each measure are important. Therefore, charts can be treated as rankings based on calculated performance indicators. 


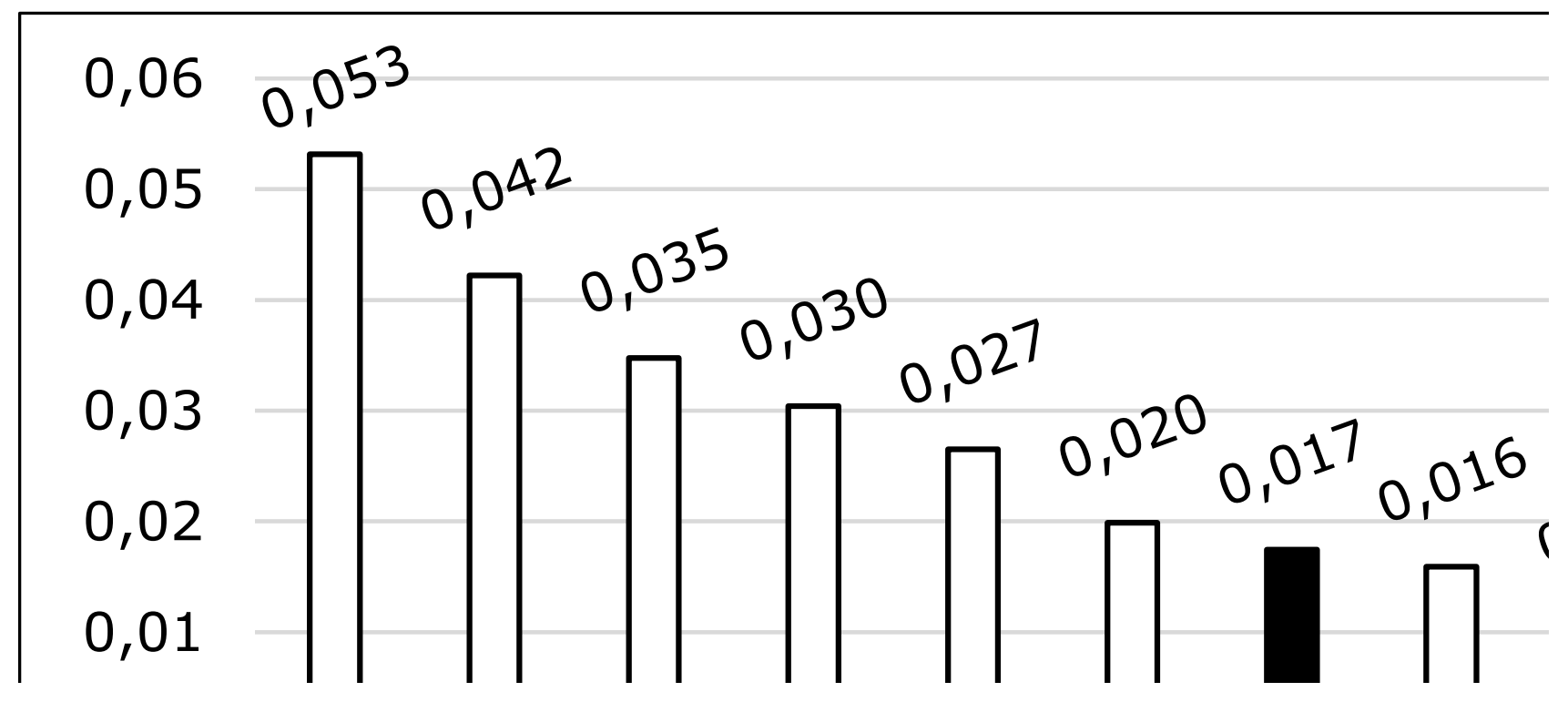

Source: author's calculations

Fig. 1. The values of Sortino coefficients ordered in descending order

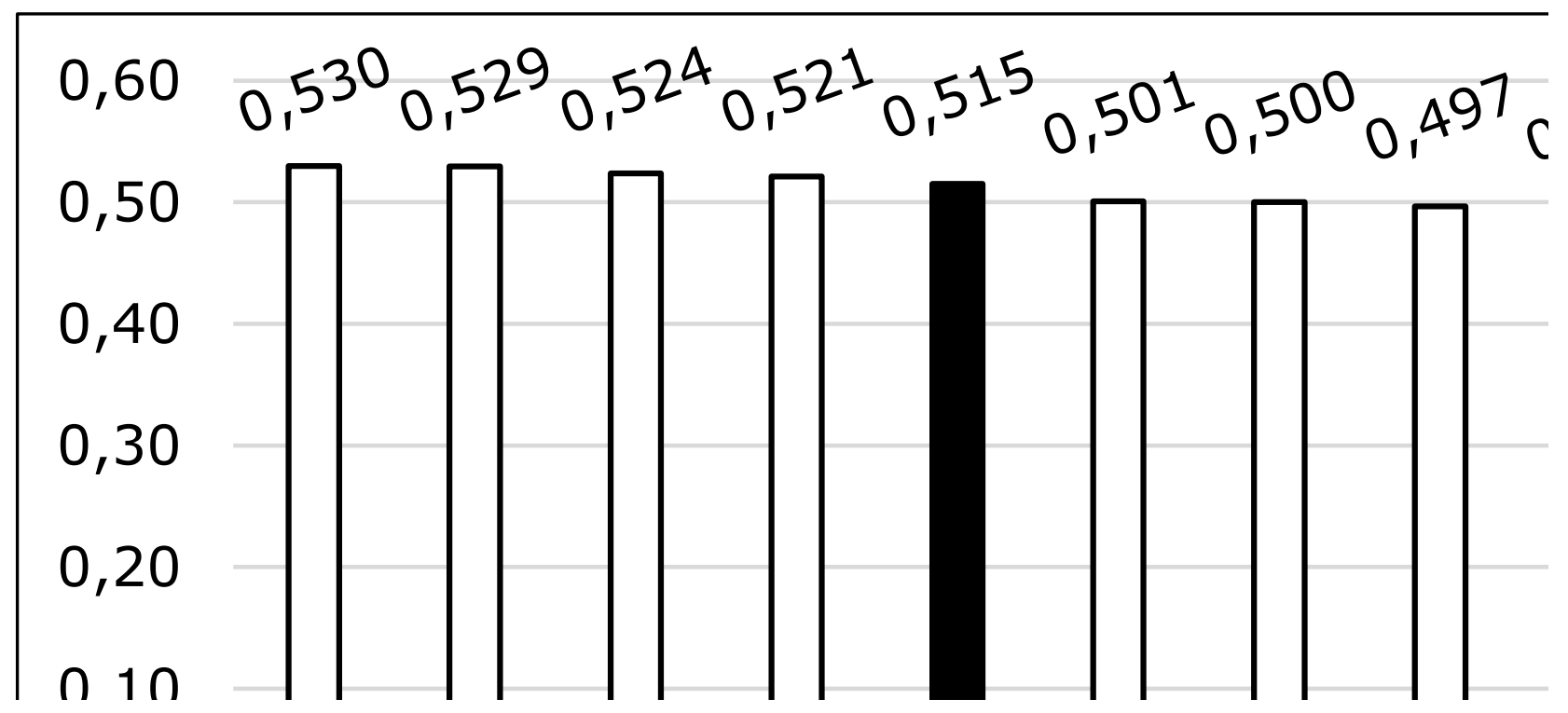

Source: author's calculations

Fig. 2. Values of UPR coefficients ordered in descending order 


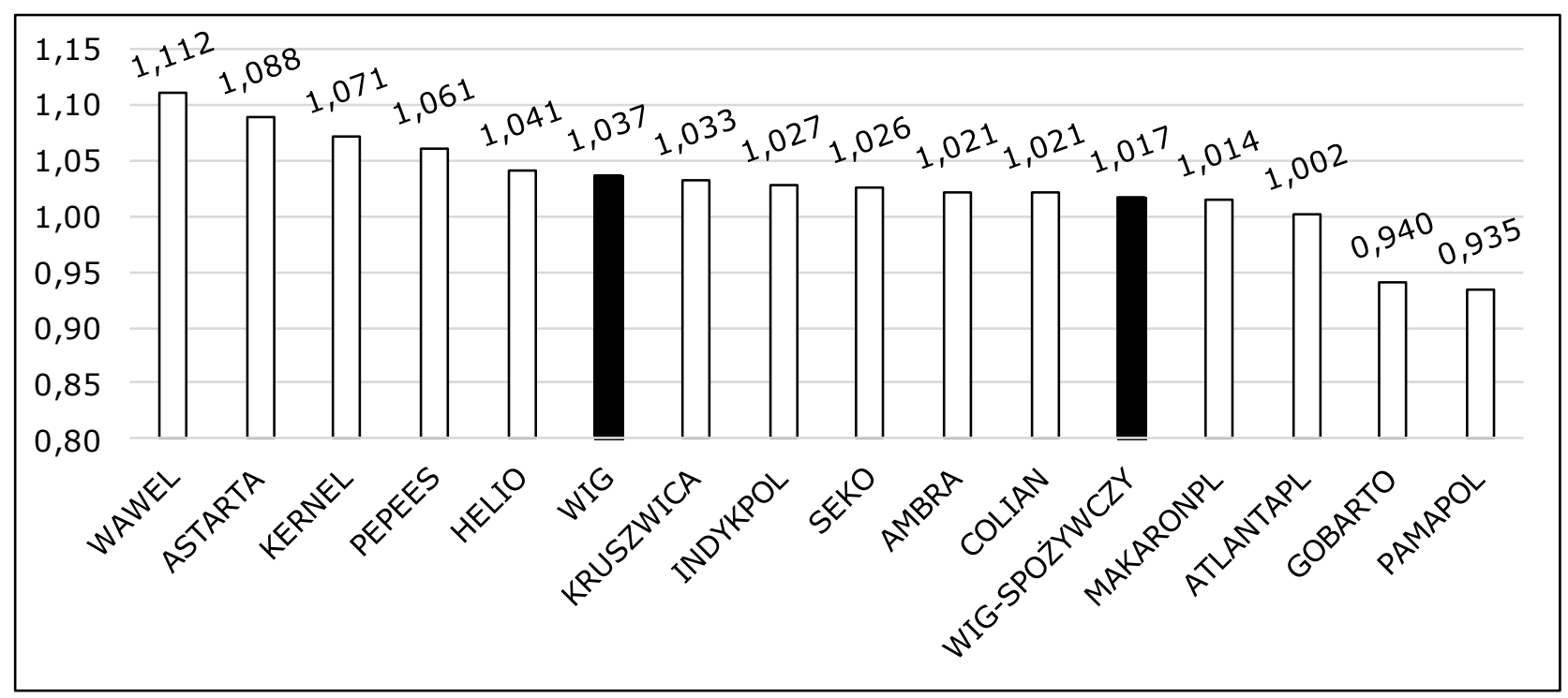

Source: author's calculations

Fig. 3. Values of Omega coefficients ordered in descending order

In the first place, it should be noted that in the case of UPR, the ratio between indices for stock exchange indices is the opposite of that for the other two. In this highlighted case, WIG-food was characterized by a higher value than WIG. However, this does not significantly change the fact that in all cases almost the same entities occupy better positions than the stock market index, they are: Wawel, Astarta, Kernel. On the other hand, Helio only falls below the industry index in the case of UPR. It can be additionally noted that from the point of view of the Sortino index, Ambra joins the group of entities with the values of a measure larger than the market (in this case WIG). As a consequence, it can be concluded that all three performance indicators are branded by the same market leaders: Wawel ${ }^{1}$, Astarta, Kernel, Pepees. Two of them: Kernel and Astarta are Ukrainian companies with a very wide range of food activities. In terms of capitalization, they occupy the first and third place respectively in the WIG-food index. Astarta is second only to Wawel. However, among the leaders of the ranking, Pepees occupies quite a distant position. The chart below shows the percentage shares of the surveyed companies in the WIG-food index.

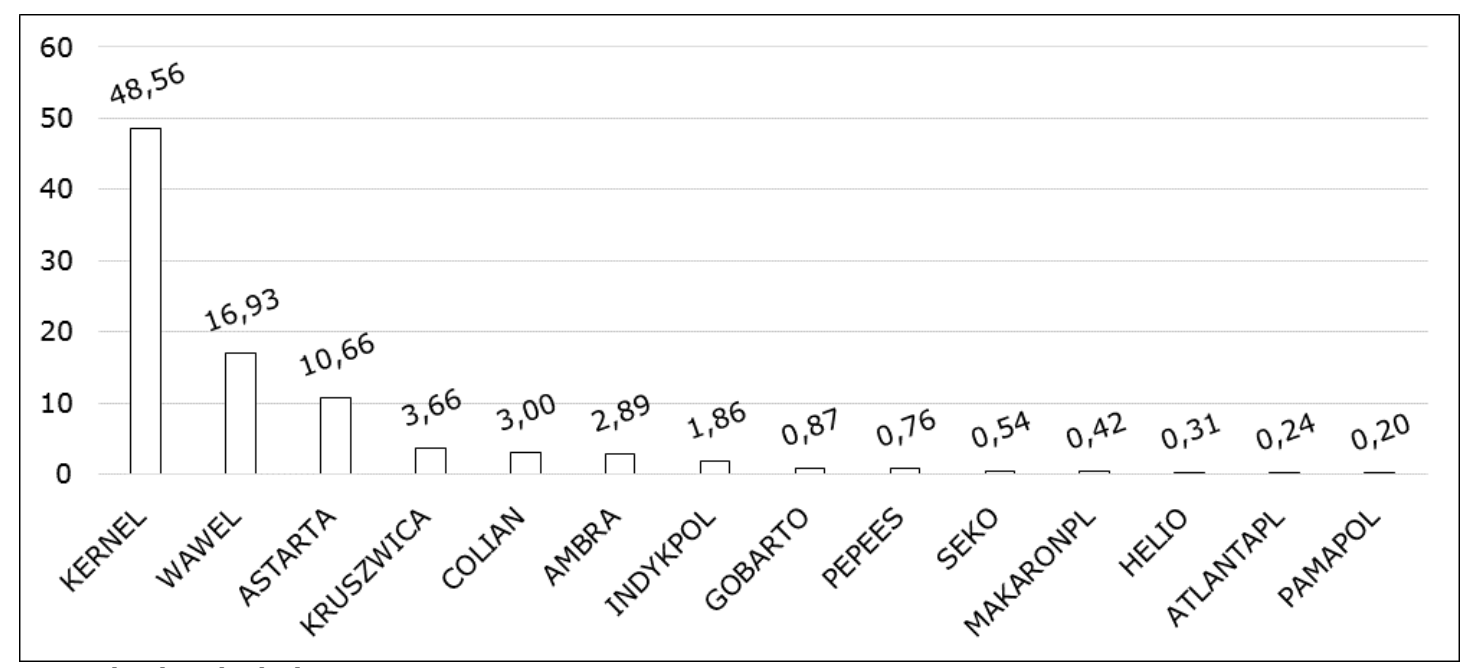

Source: author's calculations

Fig. 4. The percentage share of the surveyed companies in the WIG-food index capitalization

${ }^{1}$ Wawel also took the first place in the ranking created by using the TMAI measure in 2003 (Zielinska-Sitkiewicz, 2017) 
The three largest companies in terms of capitalization have a $76 \%$ share in the index. It should be clearly emphasized that the leaders of rankings based on Sortino and Omega coefficients occupy positions above the index of the entire WIG market. $n$ these cases, the WIG-food item is significantly lower than WIG.

The last chart may suggest that the size of the company is of significant importance to the ranking position. To verify this statement, Spearman's rank correlation coefficients were calculated between the rankings created on the basis of the indicators used and the ordering of companies according to their capitalization (percentage share in WIG-food). As a result, the following values

were obtained: $\rho_{\text {Sortino }}=0,714, \rho_{\text {UPR }}=0,450, \rho_{\text {Omega }}=0,675$. However, at the significance level of 0.05 , the Spearman correlation coefficient calculated for the UPR-based rankings turned out to be statistically insignificant. As a consequence, the remaining rankings can be linked to the capitalization of companies. However, the values of rank correlation coefficients are not too high. This means that from the point of view of investment efficiency, capitalization is not the only factor influencing investors' attractiveness, although it cannot be ignored.

On the other hand, the calculated Spearman rank correlation coefficients between the positions created on the basis of Sortino, UPR and Omega indices indicate the existence of dependence of rankings. All values turned out to be statistically significant at the significance level of 0.05 . These

values were: $\rho_{\text {Sortin/UPR }}=0,824, \rho_{\text {Sortinol Omega }}=0,956, \rho_{\text {Omega/UPR }}=0,785$. The largest relationship occurred between the rankings obtained using the Sortino and Omega ratios.

\section{Conclusions, proposals, recommendations}

1) The results of the research carried out show that there are companies in the food sector that are attractive from the investment point of view. The calculated measures of effectiveness indicate large entities in terms of capitalization. However, it turns out that this may not be the only factor determining the company's choice. Of the three measures of effectiveness applied, the UPR coefficient leads to Spearman's zero ranking correlation of the ranking created and the ranking of companies in terms of capitalization. Other indicators have moderate values, but statistically different from zero. As a consequence, the explanation of ranking positions requires the identification of other factors beyond capitalization.

2) Comparison of the calculated measures with their values for the WIG stock index indicates that the food industry can find attractive companies from the point of view of the entire exchange market.

3) Continuation of the presented research requires the identification of other factors determining the value of efficiency ratios beyond capitalization. In the first step, the food industry can be linked to the state of the entire economy by building models with macroeconomic factors. Further refinement of the research should lead to econometric models for specific companies, with explanatory variables related to the factors resulting from the fundamental analysis.

\section{Bibliography}

1. Dobosz, M. (2004). Wspomagana komputerowo statystyczna analiza wynikow badan. Akademicka Oficyna Wydawnicza EXIT, Warszawa.

2. Luszniewicz, A., Slaby, T. (2003). Statystyka z pakietem komputerowym STATISTICA PL. Wydawnictwo C.H. BECK, Warszawa.

3. Shadwick, W., Keating, C. (2002). A Universal Performance Measure. Journal of Performance, pp. 59-84.

4. Sortino, F. Price, L. (1994). Performance Measurement in a Downside Risk Framework. Journal of Investing, 3(3), pp. 59-64. 
Proceedings of the 2018 International Conference "ECONOMIC SCIENCE FOR RURAL DEVELOPMENT" No 49

Jelgava, LLU ESAF, 911 May 2018, pp. 196-203

DOI 10.22616/ESRD.2018.136

5. Sortino, F., Van der Meer, R. Plantinga, A. (1999). The Upside Potential Ratio, Journal of Performance Measurement, 4(1), pp. 10-15.

6. Zielinska-Sitkiewicz M. (2017). Classification of selected food industry companies listed on the Warsaw Stock Exchange - the impact of normalization procedures. Proceedings of the 2017 International Conference "ECONOMIC SCIENCE FOR RURAL DEVELOPMENT", No 46, Jelgava pp. 359-366. 